International Journal of Engineering \& Technology, $7(2.33)(2018) 553-556$
International Journal of Engineering \& Technology
Website: $w$ ww.sciencepubco.com/index.php/IJET
Research paper

\title{
Bench marking of grid tied solar roof top photovoltaic system: a case comparison
}

\author{
Sudhir.S. Chopade ${ }^{1}$, Lalith Pankaj Raj. G. ${ }^{2} *$, Prabakaran.G ${ }^{2}$ \\ ${ }^{1}$ Faculty, REC_Institute of Power Management and Training, Telangana, India. \\ ${ }^{2}$ M.Tech Scholar, Centre For Rural Energy, The Gandhi gram Rural Institute-Deemed to be University, Tamil Nadu, India. \\ *Corresponding author E-mail: lpraj1995@gmail.com
}

\begin{abstract}
Indian power sector having the target of $175 \mathrm{GW}$ of power from renewable energy, out of that $40 \mathrm{GW}$ from Rooftop solar Photovoltaic system by 2022. The installed capacity of solar photovoltaic until 2017 is about $14.77 \mathrm{GW}$ only. Even though in depth study has been carried out on the performance analysis, there is no bench marking has been arrived for the Indian Roof Top Solar PV system. Hence this paper has made an attempt by calculating the various parameters like performance ratio, plant capacity utilization ratio for the two $20 \mathrm{KWp}$ grid connected rooftop power plant in Telangana state. In addition to the above, it needs to do in depth analysis of power quality issues on roof top grid tied system.
\end{abstract}

Keywords: Capacity Utilization Factor; Grid Connected; Performance Ratio; Solar Photovoltaic Rooftop.

\section{Introduction}

Due to the rapid rise in the global energy demand and stringent environmental regulations, paradigm shift towards renewable and clean energy sources emerges in the scenario. Out of all the renewable energy sources, solar photovoltaic technology possess a top ranker position.

This $21^{\text {st }}$ century is known to the renewable Era, where the growth of renewable energy has seen a remarkable milestone in order to show the huge difference in the Indian power sector. India has an enormous amount of solar energy about 5000 trillion kwhr per year, with an average of 4-7 Kwhr per sq. meter per day.

\section{Literature review}

Ashish Verma and Shivya Singhal et al., [1] explains the basic concepts of performance analysis and optimal plant operation of the solar photovoltaic power plant in a MW scale. Here all the parameters and factors that to be consider while calculation of the performance ratio, in order to get the quality of the photovoltaic plant and also dealt with simulation of the plant in order to dealt with in-depth comparison of various losses of the plant. The capacity utilization factor of the fixed solar plant is about 18 $19 \%$. Therefore Indian power plant will give $0.18 \mathrm{MW}$ of power from $1 \mathrm{MW}$ capacity plant.

Ankit Kumar Sarraf, Sunil Agarwal, Dinesh Kumar Sharma [2] gave a detailed case study on comparison of solar Photovoltaic power plant of MW scale. Here they discussed about the performance ratio and capacity utilization factor calculation of the MW scale plant based upon their previous year data logging with all metrological measurements in it. Thus this clearly gives an idea about, how the plant performance is varying according to the environmental parameter like temperature and grid availability.
Tahira Bano, KVS Rao et al., [3] gave the detailed performance study of grid connected utility scale power plant, they worked out with the various methods of performance calculation like Excel workbook, PVSyst and System advisory model and dealt with the variation of results from each method of performance calculation. Detailed parameters like reference yield, array yield, final array yield, system losses, interest rate and inflation rate are calculated to achieve the state of accuracy. Three years of data are taken into the calculation for obtaining the calculation of levelized electricity cost of generation.

K. Pritam Satsangi, D. Bhagwan Das, A.K. Saxena et al., [4] gave the detailed study that carried out to the KW scale solar photovoltaic power plant based on the IEC 61724 standards by calculating various parameters like performance ratio, final and reference yield, capacity utilization factor for the plant capacity of $40 \mathrm{KWp}$ power with comparing that with the convention solar power sharing with the battery charging, to grid and to the Load.

\section{Plant details}

Fig.1 shows the actual 20KWp solar Photovoltaic rooftop power plant located in the Rural Electrification Corporation Institute of Power Management and Training, Shivarampally, Hyderabad. The annual average solar Insolation of the particular site is about 5.44 KWHr per $\mathrm{m}^{2}$. [5]

Fig. 2 gives the entire solar Photovoltaic rooftop layout, where all the interconnections and terminations of the plant are given. Here as mentioned previous that, each array of the plant is connected with 10 Modules of each $250 \mathrm{Wp}$ Polycrystalline module rated are connected serially to form a single array; thereby eight array of modules are obtained in the terminals. 


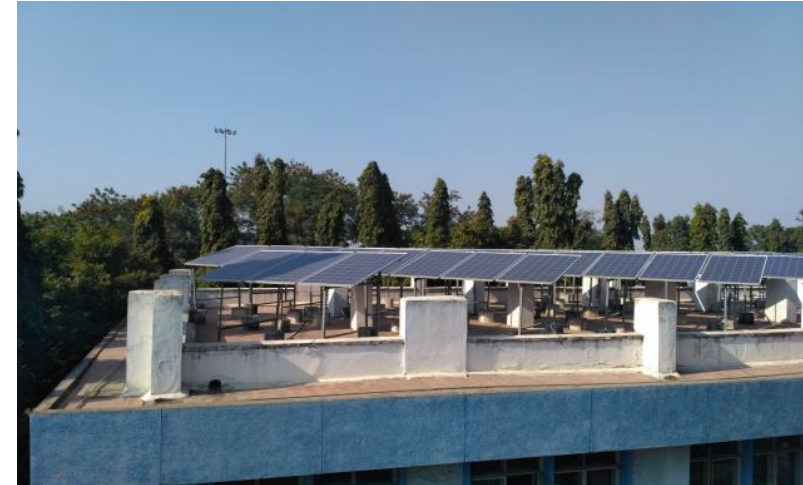

Fig. 1: Actual Plant Image.

Table 1: Specifications of Plant under Study

\begin{tabular}{lll}
\multicolumn{3}{c}{ Table 1: Specifications of Plant under Study } \\
\hline S.NO & Plant Details & \\
\hline & Parameters & Details \\
1 & System Capacity & $2 * 20 \mathrm{KWp}$ \\
3 & Longitude & 78.486670 \\
4 & Latitude & 17.3830 \\
5 & Tilt Angle & $18-20$ \\
6 & Type of Module & Poly Crystalline \\
7 & Module Efficiency & $15.53 \%$ \\
8 & Inverter & 20 KW grid tied \\
9 & Controller & MPPT type \\
\hline
\end{tabular}

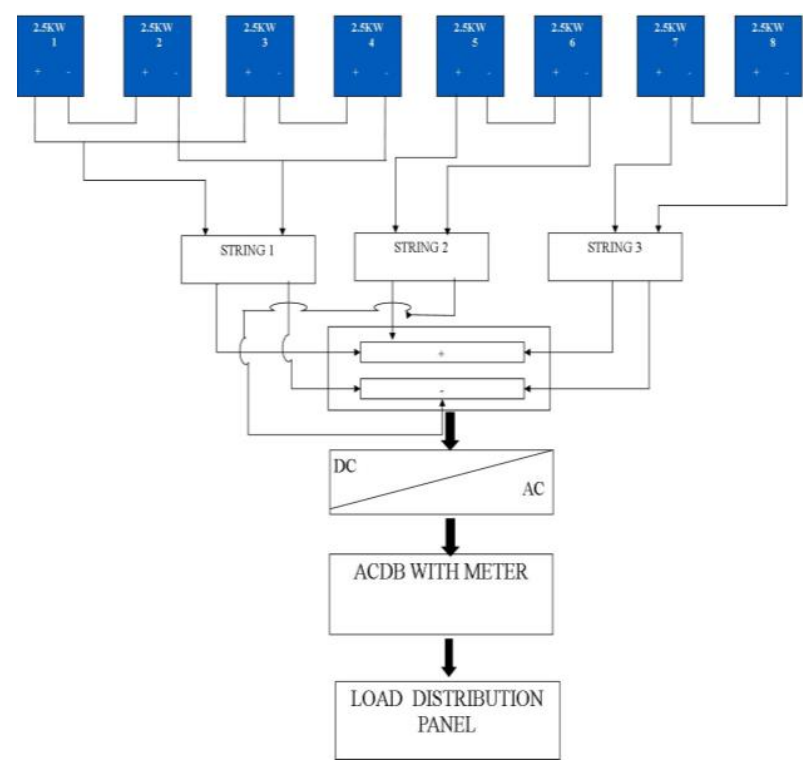

Fig. 2: Layout of Two-20kwp Solar Power Plant.

Table. 1 gives the detailed parameters like plant capacity of two 20 KWp grid connected plant without any tracking mechanism. Placement of modules in the structure at the tilt angle of $18-20^{\circ}$ with south orientation. All the modulus are fixed above 2 Meter height from the rooftop.

Table. 2 gives the detailed panel specification of the system under study. All the panels are air ventilated in nature to reduce the overall module temperature shoot-ups.

Table 2:.Panel Specification Details

\begin{tabular}{lll}
\hline S.NO & Panel Specifications & \\
\hline & Parameters & Details \\
1 & Rated power & $250 \mathrm{Wp}$ (Tolerance $+/-3 \%)$ \\
2 & Vmp & $30.36 \mathrm{volt}$ \\
3 & Imp & $8.25 \mathrm{Amps}$ \\
4 & Voc & $37.2 \mathrm{Volt}$ \\
5 & Isc & $8.70 \mathrm{Amps}$ \\
6 & Max System Voltage & $600(\mathrm{USA}), 1000(\mathrm{EU})$ \\
7 & Standard Test Condition & $1000 \mathrm{~W} / \mathrm{M}^{2}, \mathrm{AM}=1.5,25^{\circ} \mathrm{C}$ \\
8 & Make & Empire, EPG 250 \\
\hline
\end{tabular}

Then eight arrays of modules are again connected serially to for a four string groups, out of four string groups two were connected parallel to achieve three string output from the power plant. Three string outputs from the power plant are directly fed into the power inverter for inversion process.

The power inverter is having the technology of Maximum Power Point Tracking (MPPT) with Grid tied facility to achieve maximum power generation in the sunshine hour. Finally system is reaching the load distribution panel of the campus through the Alternating Current Distribution Box with Metering system. Along with this plant layout the continuous plant monitoring system with cloud storage are also enabled.

\section{Performance analysis}

Performance analysis is the vital parameter to analyze the performance of a solar photovoltaic plant and that is free from locality. It is defined in International Electrotechnical Commission (IEC) 61724 standards clearly about the performance analysis limits and describes the association between the definite and theoretical energy generation of the photovoltaic system despite of many derating parameters viz. inverter inefficiency, cable losses, cell mismatch losses, module temperature losses, Module glass surface Reflection from, soiling losses, grid instability, shading losses and any other instruments failures.

\subsection{Capacity utilization factor}

Capacity Utilization Factor is a vital parameter to study the plant load factor. This capacity factor is not going to take the environmental parameters like effects of irradiance, temperature of the module and even the photovoltaic modules degradation effects. Important parameter like grid availability is also not taken in to the account for the capacity factor calculation. Capacity is the highest generation yield of a power plant, generally measured in KW, MW or GW capacities.

Capacity Utilization Factor of a solar photovoltaic plant are mainly by the ratio of the energy measured or energy output to the product of annual duration and the installed capacity of the plant,

$C U F=\frac{\text { EnergyMeasured }(\text { Kwhr })}{(365 * 24 * \text { Installed capacity })}$

Solar energy generation is mainly depending on the two parameters like solar radiation received and clear sunny in the plant location. According to the MNRE report of 2013, average plant capacity utilization factor of the solar power plant of India are ranges between $15-19 \%$.

Therefore it is not acceptable that the capacity utilization factor is a just right parameter to be considered, while taking the performance of the solar photovoltaic power plants. Future, the capacity utilization factor of the power plant is calculated for 24 hours of duration, which is not in the case of solar photovoltaic power plant because, solar power generation is not for 24 hours.

It is only for sunshine hours of maximum of 6-8 hours. So, it is not fare to compare capacity utilization factor of solar photovoltaic power plant with conventional power plants like thermal power plants.

\subsection{Performance ratio}

Performance ratio is a measure of quality of the solar photovoltaic power plan, therefore it describes as a quality factor of the power plant. Performance ratio is measure of how effectively the power plant converts the sunlight collected by the Photovoltaic module into AC energy generation. The equation for calculating the performance ratio are given in the equation no. (2)

$P R=\left(\begin{array}{c}\sum E N \mathrm{ACi} \\ \left(\sum P \mathrm{STC}\left(\frac{G \mathrm{POA} i \mathrm{i}}{G \mathrm{STC}}\right)\right)\end{array}\right)$ 
The summations are over a defined period of time that may be days, weeks, months, years

$\mathrm{PR}=$ performance ratio (unit less)

ENAC $=$ measured $\mathrm{AC}$ electrical generation $(\mathrm{kW})$

PSTC $=$ summation of installed modules' power rating from flash test data $(\mathrm{kW})$

GPOA $=$ measured plane of array $($ POA $)$ irradiance $(\mathrm{kW} / \mathrm{m} 2)$

$\mathrm{i}=\mathrm{a}$ given point in time

GSTC = irradiance at standard test conditions $($ STC) $(1,000$ $\mathrm{W} / \mathrm{m} 2)$

$$
P R=\frac{\text { Actual Energy Generated }}{\text { Energy Estimated }}
$$

The closer the performance ratio value to $100 \%$, the plant is said to be operating in a good condition. In real case, the $100 \%$ attainment is not a possible due to temperature effects of the modules and other various losses.

\subsection{Factors affecting performance ratio}

Performance ratio is purely based on the variable that are all prescribed as a standard test condition (STC) like $1000 \mathrm{~W} / \mathrm{M}^{2}$ and $25^{\circ} \mathrm{Celsius}$ of module temperature. There are various performance parameters, which plays a huge role in performance ratio calculations.

Parameters are further classified into Environmental and external effects. The Environmental parameters like, Module temperature, Solar Insolation, Shading effect of the plant and external parameters like Cleaning, ageing of modules.

\subsection{System net loss}

The overall system net loss are the summation of capture loss and system loss. Capture loss of the plant defined by the difference between the reference yield and array yield. Difference between the array yield and final yield is generally termed as System loss. A perfect plant should have less amount of system net loss. This loss analysis also can state the overall performance of the system.

\section{Results and discussions}

\subsection{Capacity utilization factor}

Based on the detailed analysis and comparison of the two grid connected plants are graphically represented in the Fig.2. From our detailed study, we came to infer that the capacity utilization factor of the plant is in acceptable limits of government standards, which is a positive indicator for the rooftop system.

As per the MNRE guidelines the capacity utilization factor of solar photovoltaic power plant should be within the limits of 15$19 \%$.Here we observed the presence of in an average of 15-16\% for both the plants and maximum of $19 \%$ also reached once in the year calculation, which shows that the plant is operating in a good condition.

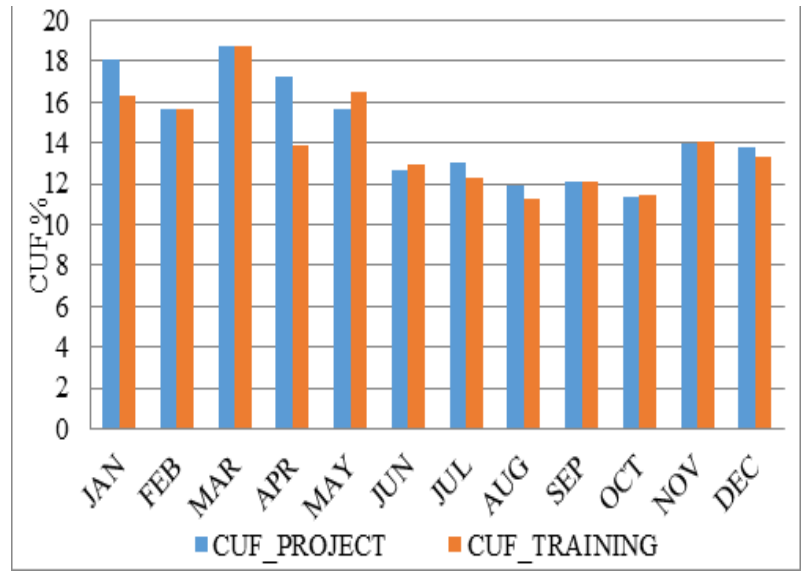

Fig. 3: Comparison of Capacity Utilization of Plant.

\subsection{Performance ratio}

Based on the calculation, the comparison of performance ratio is done for both the grid connected power plant and the performance ratio comparison is graphical represented in the Fig.5.According to the National Renewable Energy Laboratory performance ratio of solar photovoltaic system are within 0.6 to 0.9 [5].

We inferred that the performance ratio of both the rooftop system is in within the standards, which is a positive indicator for the power plant. The performance ratio of project plant site is slightly higher than that of training centre plant. This is mainly because of the various parameters that are involved in the location of the plant site. While critically looking over the performance ratio of the training centre, there is huge drop in performance during the summer season than the project centre plant, where there is higher temperature showups is noted from the metrological data of the site.

Important point to be understood that the reason of drop in performance ratio in the project site during winter solstice is mainly due to the shading effect of the site, and it is shown in the Fig.6.It is vice versa condition in the vernal equinox, where the project plant site is free from the shading effect, which is clearly evident from the boost of performance ratio of the project centre plant.

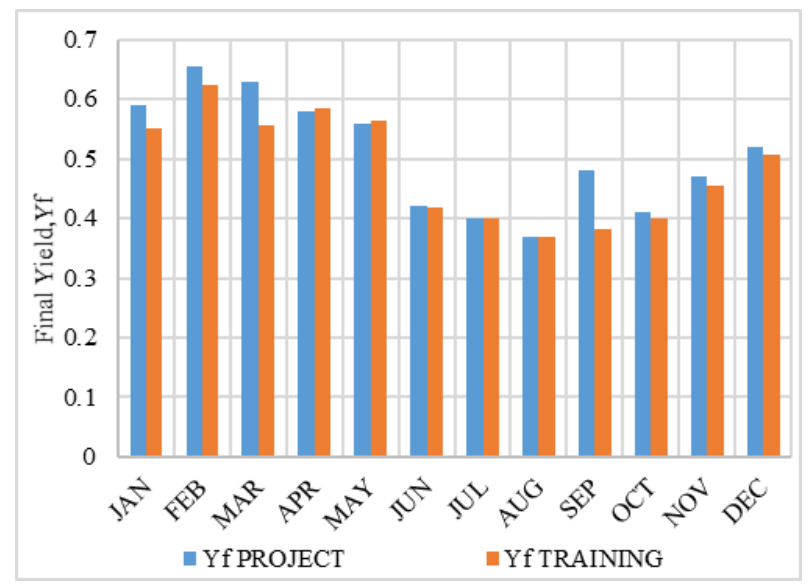

Fig. 4:.Final Yield of plant

Fig.4 graph revels that the final yield of both the plant under study, form this graph it is clearly infers that the performance of the Project centre plant is higher than the training centre plant. This is mainly due to the fact that the presence of environmental and other external factors, that are prevailing in the site of the plant under consideration. The huge drop in final yield during the period of summer shows clearly shows the effect of module temperature rise and environmental constrains. 


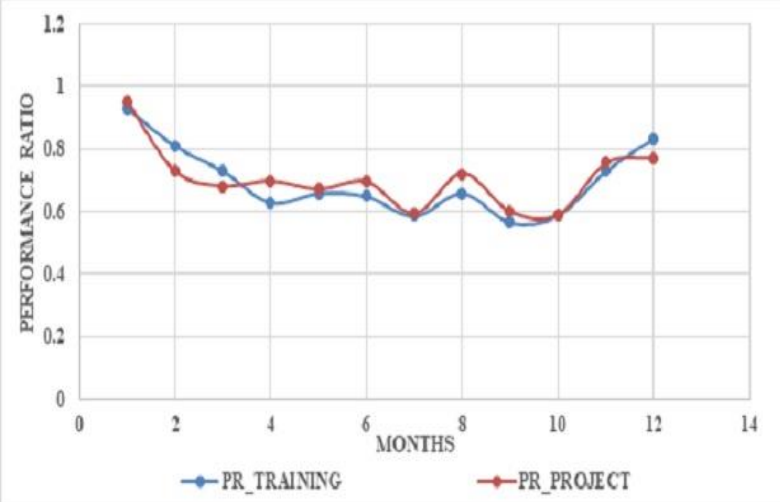

Fig. 5: Performance Analysis Comparison of Plant.

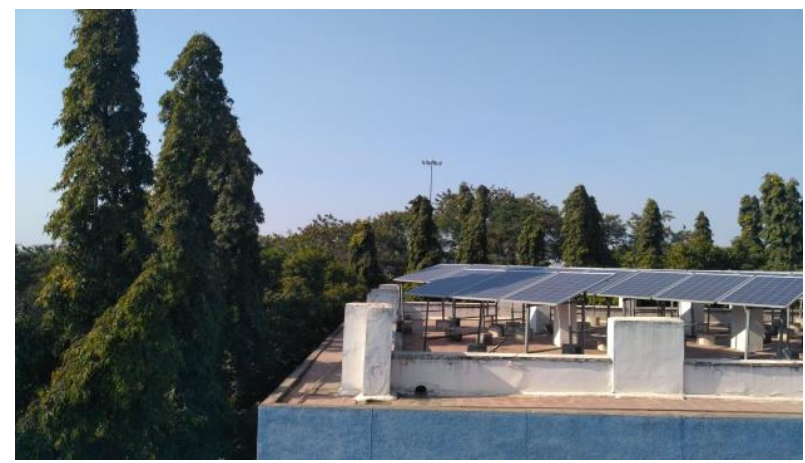

Fig. 6: Shading Effect during Winter Solstice

\subsection{System loss of plant}

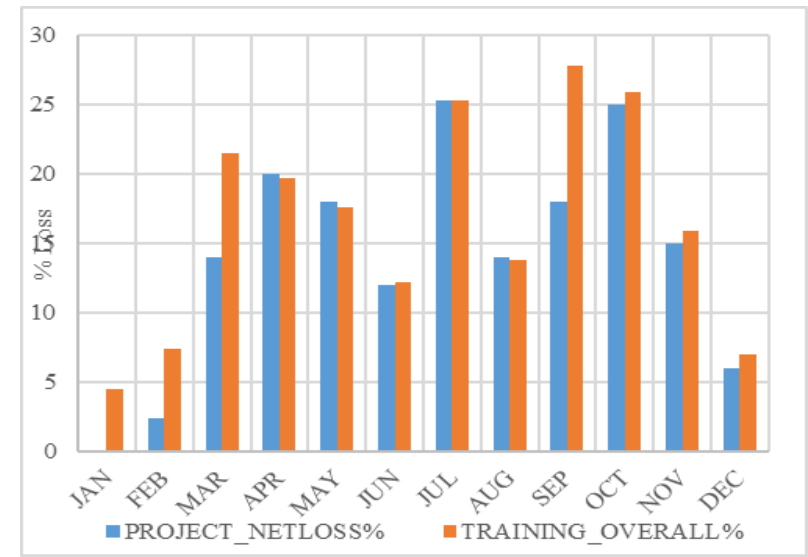

Fig. 7: Overall System Loss of Plant.

Fig.7 Shows the oveall system loss of the plant under study,it infers the overall performance of the plant.There is a hude drop in the overall system performace during the summer season, which is clealry evident in this loss calculation.(i.e) Huge percentage loss of the oveall system loss .

\section{Conclusion}

Generally, Capacity utilization factor of solar photovoltaic rooftop grid connected plant are about to be $18 \%$ - 20\%. Performance ratio of the rooftop plant are about to be nearer to 1.Overall system Net loss of the grid connected solar grid connected plant should be very minimum or to be zero to achieve the overall good performance of the plant. From our detailed study we found that the both the plant having are within the standard values.

From the analysis of Performance ratio during the winter season Training centre plant has higher ratio than the project centre plant, This is mainly due to the vernal equinox shadowing effect of the trees that are located in the training centre site. Other than winter season, like pre monsoon, monsoon and post monsoon seasons, and the overall performance ratio of project centre is higher than the training centre. Thus, the overall performance ratio of project centre are better than the training centre.

\section{Acknowledgement}

The authors gratefully acknowledge Rural Electrification Corporation Institute of Power Management and Training for giving opportunity for carry out the analysis work and University Grants Commission for funding the M.Tech, Renewable Energy under Innovative Program scheme.

\section{References}

[1] Ashish Verma and Shivya Singhal, "Solar PV Performance Parameter and Recommendation for Optimization of Performance in Large Scale Grid Connected Solar PV Plant-Case Study," J. Energy Power Sources Vol. 2, No. 1, 2015, pp. 40-53 Received: August 6, 2014, Published: January 30, 2015

[2] Ankit Kumar Sarraf1, Sunil Agarwal2, Dinesh Kumar Sharma 3 , "Performance of $1 \mathrm{MW}$ Photovoltaic System in Rajasthan: A Case Study,"IEEE $7^{\text {th }}$ Power India International Conference(PICON)., 978-1-4673-8962-4/16/\$31.00 @2016 IEEE

[3] Tahira Bano, KVS Rao., "Performance analysis of 1MW grid connected photovoltaic power plant in Jaipur, India," 978-1-46739925-8/16/\$31.00 @2016 IEEE

[4] K. Pritam Satsangi, D. Bhagwan Das, A.K. Saxena., "Performance Analysis Of 40kwp Solar Photovoltaic Plant,'IEEE Region 10 Humanitarion technology conference 2016, R10-HTC-Proceedings.

[5] Ajit.P.Tyagi., "Solar Radient Energy Over India" by Ministry of New and Renewable Enegy.200.

[6] Sarah Kurtz., "Weather Corrected performance Ratio,"Technical report NREL/TP-5200-57991,April 2013. 